\title{
Factor Analysis of Metabolic Syndrome in Aged Population Undergoing Periodical Health Examinations
}

\author{
Hsiao-Hui Chiu ${ }^{1,2}$ \\ ${ }^{1}$ Taipei Veterans General Hospital, Taipei, Taiwan \\ ${ }^{2}$ Department of Nursing, National Taipei University of Nursing and Health Sciences, Taipei, Taiwan \\ Correspondence: Hsiao-Hui Chiu, No. 201, Sec. 2, Shipai Rd., Beitou District, Taipei 11217, Taiwan.
}

Received: March 14, 2020

Accepted: March 27, 2020

Online Published: April 15, 2020

doi:10.20849/ijsn.v5i2.725

URL: https://doi.org/10.20849/ijsn.v5i2.725

This research was by an intramural grant of Taipei Verterans General Hospital (V107A-036). The funders had no role in the design of the study; in the collection, analyses, or interpretation of data; in the writing of the manuscript, or in the decision to publish the results.

\begin{abstract}
Background: Metabolic syndrome (MetS) is a common health problem in aged people. The cluster of diseases associated with MetS, namely, heart disease, cerebrovascular disease, diabetes, hypertensive disease and renal disease, had made a death rate of $0.17 \%$, higher than $0.15 \%$ attributed to cancers.

Aims: To investigate the prevalence, incidence and reversion rate of MetS in Aged population undergoing periodical health examinations, as well as the associated impact factors.

Results: The prevalence of MetS was found to be $19.9 \%$ among all the subjects studied, to be higher in female $(23.1 \%)$ than in male $(18.3 \%)$. The incidence of MetS was $17.6 \%$. In contrast, the reversion rate of MetS was $45.0 \%$. Sex $(p=0.045)$ and history of hyperlipidemia $(p=0.006)$ were two factors found to be significantly associated with the reversion rate of MetS.

Conclusion: Physical examinations may help early detect diseases and revise high risk factors timely. Compared with the ordinary older population, those undergoing periodical health examinations tended to have lower incidence of MetS, better health status and higher disease reversion rate than incidence. To sum up, individualized health education and guidance is an imperative and critical nursing intervention to ensure a healthy state for aged population.
\end{abstract}

Keywords: metabolic syndrome, aged, health examinations

\section{Introduction}

Metabolic syndrome (MetS) is a common health problem in aged people. According to the report of the top 10 causes of death issued by the Ministry of Health and Welfare of Taiwan in 2017, the cluster of diseases associated with MetS, namely, heart disease, cerebrovascular disease, diabetes, hypertensive disease and renal disease, had made a death rate of $0.17 \%$, higher than $0.15 \%$ attributed to cancers. MetS is significantly associated with chronic diseases. Compared with non-MetS patients, MetS patients run1 to 4 times higher risks of cardiovascular disease and diabetes. Diabetic patients with MetS make 4.9 times higher incidence of cardiovascular disease than those without MetS (Montazerifar, Bolouri, Mahmoudi Mozaffar, \& Karajibani, 2016). Patients with MetS also have higher risk of colorectal cancer, breast cancer, pancreatic cancer, prostate cancer, and gastric cancer (Hu et al., 2017; Uzunlulu, Telci Caklili, \& Oguz, 2016). The prevalence of MetS tends to increase with age. A systematic literature review on the prevalence of MetS among the Asian Pacific adults yielded the result of $16.5 \%$ (17.2\% in male v.s. $16.0 \%$ in female) in Japan. In Taiwan, it was $25.5 \%$ (25.5\% in male vs. $31.5 \%$ in female), and tended to continuously run up high (Ranasinghe, Mathangasinghe, Jayawardena, Hills, \& Misra, 2017). Another research suggested the MetS prevalence of $29.0 \%$ in the older population in Taiwan (21.6\% in male v.s. $38.2 \%$ in female) (Abbasi-Ghahramanloo, Soltani, Gholami, Erfani, \& Yosaee, 2016). In Iran, the adult prevalence of MetS was $49.5 \%$ ( $40.2 \%$ in male vs. $55.9 \%$ in female) (Montazerifar et al., 2016). In the US, the prevalence was higher than 25\% (Abbasi-Ghahramanloo, Soltani, 
Gholami, Erfani, \& Yosaee, 2016), while in Amsterdam, the prevalence and incidence of community residents aged 55 to 85 years were $37 \%$ and 30\%, respectively (Van Ancum et al., 2018).

MetS is defined as at least three of the following metabolic risk factors to be diagnosed with: waist circumference ( $\geq \mathrm{cm}$ for males, $\geq 80 \mathrm{~cm}$ for females), blood pressure (systolic $\geq 130 \mathrm{mmHg}$ or diastolic $\geq$ $85 \mathrm{mmHg}$ ), fasting blood glucose $\geq 100 \mathrm{mg} / \mathrm{dL}$, HDL-C ( $<40 \mathrm{mg} / \mathrm{dL}$ for males, $<50 \mathrm{mg} / \mathrm{dL}$ for females), and triglyceride $>150 \mathrm{mg} / \mathrm{dL}$ (Montazerifar et al., 2016). Other compound factors are old age, higher BMI, living with family members, lower level of education, lack of physical exercise, female, obesity, and family history (Franca, Lima, \& Vieira, 2016; Lin et al., 2015; Montazerifar et al., 2016; Roos et al., 2017). Predictors of MetS in community older adults include heart disease, peripheral artery disease, diabetes, cerebral stroke and higher BMI (Van Ancum et al., 2018).

On the other hand, healthy lifestyle such as habits of sufficient exercise, abstinence from smoking and betel nut chewing, and well-controlled dietary pattern is statistically associated with low incidence of MetS (Leonie et al., 2014). Pritikin's research (2018) suggested that compared with taking medications, health education and lifestyle changes were more effective in reversing MetS. Healthy diet and regular exercise had 2 to $1 / 2$ times higher effect than medications in elimination of MetS. Health management and education may enhance our self-awareness and determination to take actions to change behaviors such as doing more exercise and keeping on healthier diet to promote our own health (Lo, Chair, \& Lee, 2015). Going on a diet and control of weight are beneficial for the reversion of MetS (Ferland \& Eckel, 2012).

Taipei Veterans General Hospital has on a regular basis provided the chances of two-stage annual geriatric health examination for residents aged $\geq 65$. Physical examination was performed at the first stage, followed by an OPD revisit 2 weeks later as the second stage for review of the results of examination and, if necessary, giving nursing guidance for abnormal items.Supposing that people willing to have health examination are better motivated to promote their own health, we performed this retrospective study to analyze, using the data from the health examination performed in 4 consecutive years from 2012 to 2015, to investigate the prevalence, incidence and reversion rate of MetS, as well as the associated impact factors, for reference to more effective nursing health education in the future.

\section{Method}

\subsection{Research Design}

This cohort study adopted retrospective data analyses.

\subsection{Participants}

Participants were the residents of the Taipei City aged $\geq 65$ to have the geriatric health examinations in Taipei Veterans General Hospital for 4 successive years between 2012 and 2015.The geriatric health examination was performed at two stages, the physical examination was conducted at the first stage, followed by an OPD revisit 2 weeks later as the second stage for review of the results of the examinations aided by a physician and giving health education and guidance for abnormal items. The participants who had MetS were given with guidelines for care of metabolic syndrome, the contents of which included diagnosis of MetS, how to make periodic surveillance, diet adjustments, exercise, abstinence from smoking and cigarettes, and relief of stress.

\subsection{Data Collection}

The results of the geriatric health examinations drawn between 2012 and 2015 from the EMD database in Taipei Veterans General Hospital were collected. Variables collected included age, sex, identity, exercise habit, medical history and medication history. The study complied with research ethics guidelines and was reviewed and approved by the Institutional Review Board of the hospital (IRB No: 2017-05-007BC)

\subsection{Data Analysis}

The data were keyed in using Excel in an anonymized encoding process. The statistical software SPSS 20.0 (IBM SPSS Inc. Chicago Illinois) was used for multiclass classification, percentage, and order. The Chi-square test was used to determine the association of age, sex, identity (veterans or non-veterans), exercise habit, medical history and medication history with the prevalence, incidence and reversion rate of MetS.

\section{Results}

\subsection{Sample Characteristics}

The participants enrolled were aged $\geq 65$ (average: $75.8 \mathrm{yrs}$ ) in their first year for entrance into the study. There were more male participants $(n=226,55.1 \%)$ than females $(n=184,44.9 \%)$, and more veterans $(n=238,58 \%)$ 
than non-veterans $(n=172,42 \%)$. Among totally 410 paticipants, $74.9 \%(n=307)$ had a habit of taking exercise more than 150 min per week, $77.6 \%(n=318)$ were with hypertension history, $14.1 \%(n=58)$ had the history of hyperlipidemia, and $10.7 \%(n=44)$ had history of hyperglycemia; $46.3 \%(n=190)$ took antihypertensive agents, and $13.2 \%(n=54)$ took antihyperlipidemic agents. No one took antihyperglycemic agents (Table 1$)$.

Table 1. Demographic information related to incidence rate and reversion rate $(N=410)$

\begin{tabular}{|c|c|c|c|c|c|c|c|c|c|c|}
\hline & & & & \multicolumn{3}{|c|}{ Incidence rate $* *$} & \multicolumn{4}{|c|}{ Reversion rate $* * *$} \\
\hline \multicolumn{2}{|c|}{ Independent vavariables } & $n$ & $(\%)$ & $p$ Value & \multicolumn{2}{|c|}{$95 \% \mathrm{CI}$} & $p$ Value & \multicolumn{3}{|c|}{$95 \% \mathrm{CI}$} \\
\hline Age & & $\begin{array}{c}65-95 \\
(\text { mean }=75.8)\end{array}$ & & 0.257 & 0.555 & -1.170 & 0.918 & 0.967 & - & 1.031 \\
\hline \multirow{2}{*}{ Sex } & Male & 226 & $(55.1)$ & 0.546 & 0.963 & -1.020 & $0.045^{*}$ & 0.421 & - & 0.991 \\
\hline & Female & 184 & $(44.9)$ & & & & & & - & \\
\hline \multirow{2}{*}{ Identity } & Veteran & 238 & $(58.0)$ & 0.851 & 0.673 & - 1.386 & 0.463 & 0.774 & - & 1.757 \\
\hline & Non-veteran & 172 & $(42.0)$ & & & & & & & \\
\hline \multirow{2}{*}{$\begin{array}{l}\text { Habit } \\
\text { Exercise }\end{array}$} & N/A & 103 & $(25.1)$ & 0.563 & 0.557 & - 1.374 & 0.244 & 0.730 & - & 1.083 \\
\hline & $\begin{array}{l}\text { More than } 150 \text { min per } \\
\text { week }\end{array}$ & 307 & $(74.9)$ & & & & & & & \\
\hline \multirow{3}{*}{$\begin{array}{l}\text { Medical } \\
\text { history }\end{array}$} & Hypertension(Yes/No) & 318 & $(77.6)$ & 0.052 & 0.996 & -2.603 & 0.667 & 0.657 & - & 1.928 \\
\hline & Hyperglycemia(Yes/No) & 44 & $(10.7)$ & 0.379 & 0.692 & -2.630 & 0.082 & 0.943 & - & 2.670 \\
\hline & Hyperlipidemia(Yes/No) & 58 & $(14.1)$ & 0.260 & 0.755 & - 1.079 & $0.006^{*}$ & 1.309 & - & 5.033 \\
\hline \multirow{3}{*}{ Medication } & Hypertension(Yes/No) & 190 & $(46.3)$ & 0.556 & 0.777 & -1.599 & 0.454 & 0.782 & - & 1.732 \\
\hline & Hyperglycemia(Yes/No) & 0 & 0.0 & & & & & & & \\
\hline & Hyperlipidemia(Yes/No) & 54 & $(13.2)$ & 0.782 & 0.451 & -1.821 & 0.092 & 0.254 & - & 1.109 \\
\hline Constant & & & & 0.438 & & & 0.106 & & & \\
\hline
\end{tabular}

$* P<0.05$

PS:

** Incidence rate: Number of new cases of MetS in current year / Number of health examinations in current year X $100 \%$

***Reversal rate: Number of cases who had MetS last year but have no MetS in the current year in health examination / Number of health examinations in current year X 100\%

\subsection{Prevalence, Incidence, and Reversion Rate of MetS}

Prevalence is all existing cases number of health examinations of MetS divided by number of health examinations in current year. The average prevalence of MetS was $19.9 \%$, to be $14.2 \%, 22.2 \%, 18.8 \%$, and $24.4 \%$ in sequence of year. The average prevalence by sex was $18.27 \%$ in male and $23.1 \%$ in female. Average incidence was $17.6 \%$, to be $14.4 \%, 19.6 \%, 14.1 \%$, and $22.2 \%$ in sequenceof year; average reversion rate was $45.0 \%$, to be $13.8 \%, 39.6 \%, 76.6 \%$, and $50.0 \%$ in sequence of year (Table 2, Table 3). 
Table 2. Prevalence, incidence \& reversion rate of MetS, by year $(N=410)$

\begin{tabular}{|c|c|c|c|c|c|c|c|c|}
\hline Year & 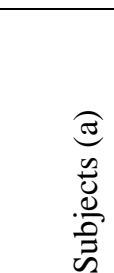 & $\begin{array}{l}\hat{e} \\
\tilde{n} \\
\sum^{2}\end{array}$ & 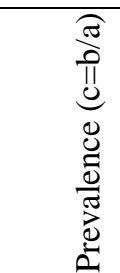 & 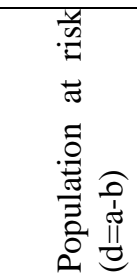 & 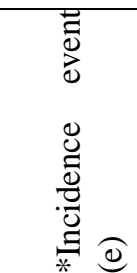 & 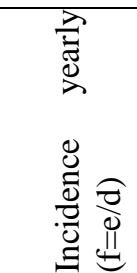 & 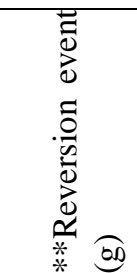 & 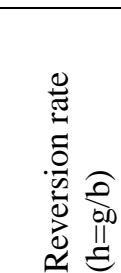 \\
\hline 2012 & 410 & 58 & $14.2 \%$ & 402 & 58 & $14.4 \%$ & 8 & $13.8 \%$ \\
\hline 2013 & 410 & 91 & $22.2 \%$ & 352 & 69 & $19.6 \%$ & 36 & $39.6 \%$ \\
\hline 2014 & 410 & 77 & $18.8 \%$ & 319 & 45 & $14.1 \%$ & 59 & $76.6 \%$ \\
\hline 2015 & 410 & 100 & $24.4 \%$ & 333 & 74 & $22.2 \%$ & 50 & $50.0 \%$ \\
\hline Average & & & $19.9 \%$ & & & $17.6 \%$ & & $45.0 \%$ \\
\hline
\end{tabular}

PS:

* Incidence event: Number of new cases of MetS in current year in health examination.

** Reversion event: Number of cases who had MetS last year but have no MetS in the current year in health examination

Table 3. Prevalence of MetS, by sex

\begin{tabular}{|c|c|c|c|c|c|c|}
\hline & Male & & & Female & & \\
\hline Year & $\begin{array}{l}\text { No. of subjects } \\
\text { (a) }\end{array}$ & $\begin{array}{l}\text { No. with MetS } \\
\text { (b) }\end{array}$ & $\begin{array}{l}\text { Prevalence } \\
(\mathrm{c}=\mathrm{b} / \mathrm{a})\end{array}$ & $\begin{array}{l}\text { No. of subjects } \\
\text { (d) }\end{array}$ & $\begin{array}{l}\text { No. with MetS } \\
\text { (e) }\end{array}$ & $\begin{array}{l}\text { Prevalence } \\
(\mathrm{f}=\mathrm{e} / \mathrm{d})\end{array}$ \\
\hline 2012 & 226 & 26 & $11.5 \%$ & 184 & 32 & $17.4 \%$ \\
\hline 2013 & 226 & 45 & $19.9 \%$ & 184 & 46 & $25.0 \%$ \\
\hline 2014 & 226 & 35 & $15.5 \%$ & 184 & 42 & $22.8 \%$ \\
\hline 2015 & 226 & 51 & $22.6 \%$ & 184 & 50 & $27.2 \%$ \\
\hline Average & & & $18.3 \%$ & & & $23.1 \%$ \\
\hline
\end{tabular}

\subsection{Relevant Impact Factors}

The correlations of the prevalence, incidence and reversion rate of MetS with variables such as sex, age, identity (veterans or non-veterans), habits of exercise, medical history and medication history were determined.

However, except that the reversion rate of MetS was found to be statistically correlated with sex and hyperlipidemia history $(P<0.05)$, no other variables showed to be the predictive factors in affecting either incidence or reversion rate of MetS.

\section{Discussion}

This study demonstrated that the prevalence of MetS in our aged participants ranged $14.2-24.4 \%$ at an average of $19.9 \%$ in four years, which is lower than $29.0 \%$ as shown in other previous research on the older adults in Taiwan region and 25\% in the US as found by Abbasi-Ghahramanloo (Abbasi-Ghahramanloo et al., 2016), and even far lower than the $37 \%$ as suggested by Van (Van Ancum et al., 2018). Our obviously better results might have to do with the stronger motivation of those who were willing to have health examination to maintain their health, and good habit of regular exercise. Both indicated healthy lifestyle behaviors.

The present study evidenced different prevalence of MetS in males (18.27\%) from females (23.1\%). Similar results were also found by Abbasi-Ghahramanloo (21.6\% in males vs. 38.2\% in females) and by Montazerifar et al. in 2016 (40.2\% in males vs. 55.9\% in females). The clearly higher prevalence of MetS in females than in males was supposed to result from the lower metabolic rate with increased body fat percentage in postmenopausal women. 
The prevalence of MetS from $14.2 \%$ in 2012 to $24.4 \%$ in 2015 showed a climbing trend similar between male and female, which conformed with the findings of Ranasinghe et al.(2017), Montazerifar et al. (2016) and Franca et al. (2016). The incidence of MetS calculated from the present study $(14.1 \%-22.2 \%$, average: $17.6 \%)$ was much lower than the value of $30 \%$ as suggested by Van et al. (2018). In Van's research, hypertension, hyperlipidemia and diabetes were found to be predictors of MetS, whereas relatively fewer participants with hyperglycemia $(10.7 \%)$ and hyperlipidemia $(14.1 \%)$ in our study made it difficult to draw any significant conclusion. Nevertheless, the incidence of MetS showed a trend rising from $14.2 \%$ in 2012 to $24.4 \%$ in 2015, similar to that of the prevalence of MetS. The reversion rate of MetS also tended to increase from $13.8 \%$ in 2012 to $50.0 \%$ in 2015 . Health education and guidance provided concomitantly with the health examination was supposed to take some effect on improving their health status, in viewing that people willing to have regular health examinations should have stronger motivation to maintain or manage a better and healthier life.

The Chi-square test was used to determine the association of incidence and reversion rate of MetS with sex, identity, habit of exercise, medical history, and use of medications. Incidence of MetS showed to be associated with none of the above-mentioned independent variables, which was different from the results found by several researchers indicating the association of the incidence of MetS with sex, age, healthy lifestyle and medical history. Although our study found higher incidence of MetS in older age and female subjects, it made no statistically significant difference.

The reversion rate of MetS in the present study was found significantly associated with sex and history of hyperlipidemia $(p<0.05)$. The association of reversion rate and sex could be readily attributed to the better compliance inhertied in behaviors of females than males. To our surprise, we did not find an association between regular exercise of $150 \mathrm{~min} /$ week and reversion rate.

According to the studies of Pritikin (2018) and Lo et al. (2015), healthy lifestyle is the most favorable factor for reversion of MetS, while Ferland \& Eckel (2012) suggested that going on a diet and maintaining weight loss facilitate the reversion of MetS. The absence of findings to confirm the association between regular exercise and reversion of MetS in this study was supposed to have something to do with the successful health eduation provided at the second stage after health examination against the abnormal results. The information related to the causes of MetS, as well as health guidelines on how to keep a healthy lifestyle such as appropriate diet and proper exercise might also take some effect on pushing them into a healthier lifestyle than before.

In the present study, $77.6 \%$ of the subjects were with the history of hypertension, $46.3 \%$ took medication; and $14.3 \%$ were with hyperlipidemia, $13.2 \%$ took medication, which suggested that medication control be the primary cause for reversion of the diseased state. The failure in finding the association between regular exercise and reversion rate remained unkown, although it might possibly be ascribed to the ambiguous classification of sports types.

\section{Conclusion}

This was a long-term study for tracing MetS from 2012 to 2015 in older population aged $\geq 65$ (agerage:75.8 yrs). The majority of them were male (55.1\%), and veterans (58.0\%). In a total of 410 subjects, $74.9 \%$ had an exercise habit of $150 \mathrm{~min}$ per week, $77.6 \%$ were with history of hypertension history, $14.1 \%$ were with hyperlipidemia, and $10.7 \%$ were with hyperglycemia; $46.3 \%$ took antihypertensive agents, $13.2 \%$ took antihyperlipidemic agents.

The incidence was $17.6 \%$ on average, and was elevated with age; reversion rate was $45.0 \%$ on average, and decreased with age. The reversion rates of MetS was statistically significantly associated with sex $(p=0.045)$ and hyperlipidemia history $(p=0.006)$. Physical examinations may help early detect diseases and revise high risk factors timely. Compared with the ordinary older population, those undergoing periodical health examinations tended to have lower incidence of MetS, better health status and higher disease reversion rate than incidence. To sum up, individualized health education and guidance is an imperative and critical nursing intervention to ensure a healthy state for aged population.

\section{Study Limitation and Recommendation}

This 4-year study might have the advantages of data collected on a long-term follow-up basis to predict a comparatively enduring trend of health status in aging population. However, limitations are enevitable since we used the data from database, which hindered us from collecting other useful data that were lack in the database, for examples, parameters related with healthy lifestyle such as dietary status, habits of smoking or drinking, etc... Health education had a positive impact on reinforcing healthy promotion behaviors. 


\section{Acknowledgements}

Collate acknowledgements in a separate section at the end of the article before the references. List here those individuals who provided help during the research (e.g., providing language help, writing assistance or proof reading the article, etc.).

\section{References}

Abbasi-Ghahramanloo, A., Soltani, S., Gholami, A., Erfani, M., \& Yosaee, S. (2016). Clustering and combining pattern of metabolic syndrome components among Iranian population with latent class analysis. Med $J$ Islam Repub Iran, 30, 445.

Ferland, A., \& Eckel, R. H. (2012). Does sustained weight loss reverse the metabolic syndrome?. Curr Hypertens Rep, 13(6), 456-464. https://doi.org/10.1007/s11906-011-0221-z

Franca, S. L., Lima, S. S., \& Vieira, J. R. (2016). Metabolic Syndrome and Associated Factors in Adults of the Amazon Region. PLoS One, 11(12), e0167320. https://doi.org/10.1371/journal.pone.0167320

Health promotion administration, ministry of health and welfare. (2018). The statistics on the cause of death of the Chinese people in 2017. Retrieved from https://www.mohw.gov.tw/cp-16-41794-1.html

Hu, D., Peng, F., Lin, X., Chen, G., Zhang, H., Liang, B., ... Niu, W. (2017). Preoperative Metabolic Syndrome Is Predictive of Significant Gastric Cancer Mortality after Gastrectomy: The Fujian Prospective Investigation of Cancer (FIESTA) Study. EBioMedicine, 15, 73-80. https://doi.org/10.1016/j.ebiom.2016.12.004

Lin, K. M., Chiou, J. Y., Ko, S. H., Tan, J. Y., Huang, C. N., \& Liao, W. C. (2015). Modifiable Lifestyle Behaviors Are Associated With Metabolic Syndrome in a Taiwanese Population. J Nurs Scholarsh, 47(6), 487-495. https://doi.org/10.1111/jnu.12163

Lo, S. W., Chair, S. Y., \& Lee, F. K. (2015). Factors associated with health-promoting behavior of people with or at high risk of metabolic syndrome: Based on the health belief model. Appl Nurs Res, 28(2), 197-201. https://doi.org/10.1016/j.apnr.2014.11.001

Montazerifar, F., Bolouri, A., Mahmoudi Mozaffar, M., \& Karajibani, M. (2016). The Prevalence of Metabolic Syndrome in Coronary Artery Disease Patients. Cardiol Res, 7(6), 202-208. https://doi.org/10.14740/cr507w

Ranasinghe, P., Mathangasinghe, Y., Jayawardena, R., Hills, A. P., \& Misra, A. (2017). Prevalence and trends of metabolic syndrome among adults in the asia-pacific region: a systematic review. BMC Public Health, 17(1), 101. https://doi.org/10.1186/s12889-017-4041-1

Roos, V., Elmstahl, S., Ingelsson, E., Sundstrom, J., Arnlov, J., \& Lind, L. (2017). Metabolic Syndrome Development During Aging with Special Reference to Obesity Without the Metabolic Syndrome. Metab Syndr Relat Disord, 15(1), 36-43. https://doi.org/10.1089/met.2016.0082

Uzunlulu, M., Telci Caklili, O., \& Oguz, A. (2016). Association between Metabolic Syndrome and Cancer. Annals of Nutrition and Metabolism, 68(3), 173-179. https://doi.org/10.1159/000443743

Van Ancum, J. M., Jonkman, N. H., Van Schoor, N. M., Tressel, E., Meskers, C. G. M., Pijnappels, M., \& Maier, A. B. (2018). Predictors of metabolic syndrome in community-dwelling older adults. PLoS One, 13(10), e0206424. https://doi.org/10.1371/journal.pone.0206424

\section{Copyrights}

Copyright for this article is retained by the author(s), with first publication rights granted to the journal.

This is an open-access article distributed under the terms and conditions of the Creative Commons Attribution license (http://creativecommons.org/licenses/by/4.0/). 